\title{
IV. MLtatizen.
}

\section{$\mathfrak{O b e r f o r f t m e i f t e r ~ D r . ~} \mathfrak{A}$. 2köller $\uparrow$}

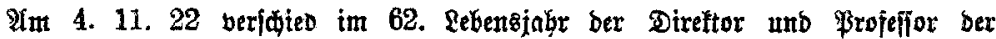

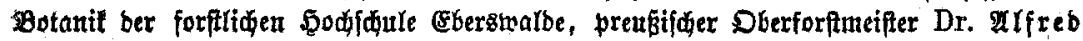

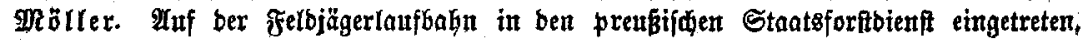

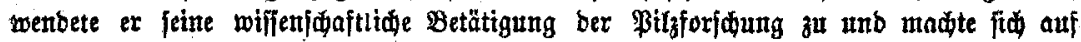
biefem Gebiste als bervorragendfter Sdjitler Brefelb etnten guten Mamen. Seine erfte größjere Irbeit ift aud zugleid bie Gedeutenbfte feines qebens gebfieben. Sie if bas

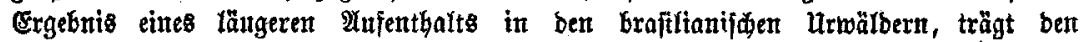

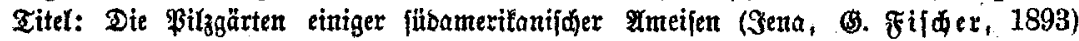

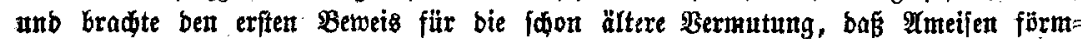

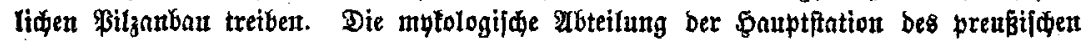

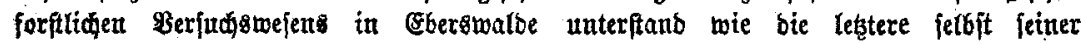

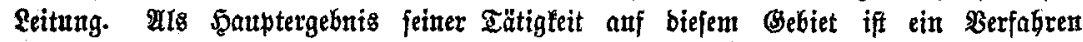

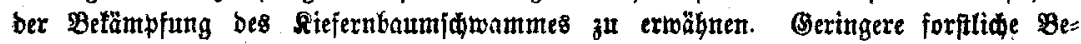

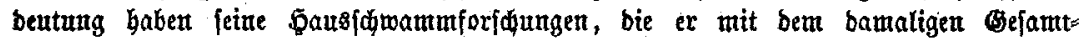

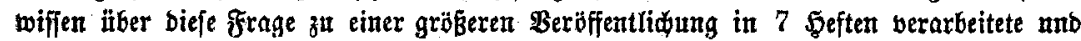

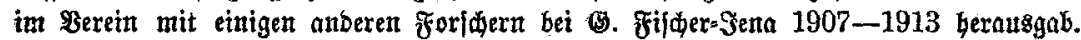
Seit 1906 war $\mathfrak{M}$ ölfer Sdriftleiter (feit 1914 alfeiniger) ber bon Dand elmann ge= grünbeten "Beitidrift für Forft= unb Sagbweien", bie aut unter jeiner Reitung iagre

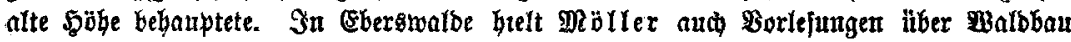
unb obmohl ex biejes fad nidjt als fein eigenftes betradjtet - lehnte ex es bod jogar ab, Forftprofefior genannt za werben - jo follte er bod gerabe mit feinen walbbauliden Sebren in ben leţten 3 Sabren groben Beifall finben. Durd bie exfolgreide Siefern= toirtichaft bes berrn von Ralitfo in Bärentboren veranlab̂t, trat er für jene Brund=

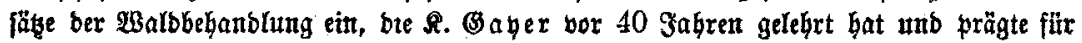

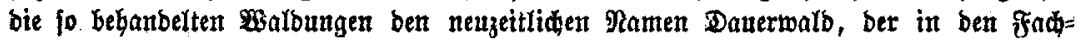
füriften uno zulests auf ber Berjammlung bes beutjdjen Forftbereins in Deffau 1922 gropien Irllang gefunben hat. Sein feffelnber Bortrag in Deffan piegelte alle wertbollen Crrungenjajaften ber Walbbajoridung unb =erfabrung feit (5) a yer wiber unb fdien

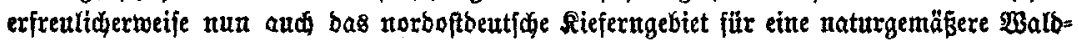
bebanblung erobert zu haben, was $\mathfrak{B}$ orggrebe Düesberg $\mathfrak{n}$. a. trob gebiegenter $\mathfrak{B}:=$ grünbung uur mangelbaft gelungen war. Sollte bem Beifall ber Bubörer bie Tat folgen,

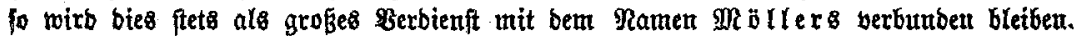

Fabricius.

\section{forittitudentenhillfe der Univerfität Gię̧en.}

\section{Aluf $\mathfrak{x} \mathfrak{u} \hat{\mathfrak{l}}$.}

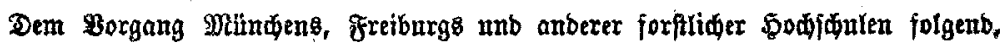
ridten aud wir an bie Rreife bes Walbbefiz̧e \$ol inbuftrie, fowie alle Freunbe Der grünen Farbe bie berglide Bitte, burd belbpenben ober fonftige Buwentungen bie Mot, in ber fí beute unfere Forftifubenten Pinben, naç Qräften Itnbern zu belfen. 